\title{
Association of breastfeeding and risk of metabolic syndrome and its components in postmenopausal parous women: Korea national health and nutrition examination survey (2010 2016)
}

Jusuk Lee ${ }^{1}$ and Taehong $\operatorname{Kim}^{2^{*}}$ (D)

\begin{abstract}
Background: Understanding the relationship between breastfeeding (BF) and metabolic syndrome (Mets) is important for maternal long-term health benefits and disease prevention. This study aimed to examine the association between BF and Mets and its components among postmenopausal parous Korean women.

Methods: This cross-sectional study on 10,356 Korean women used nationally representative data from the KNHA NES from 2010 to 2016. Anthropometric, laboratory data and manual BP were measured. A multivariate logistic regression analysis was conducted to examine the association of BF with Mets and its components after adjusting for potential confounding variables. A $p$-value $<0.05$ was to be considered statistically significant.

Results: Mets was present in $42 \%$ of the study participants. The BF group had low household income and education level. The prevalence of Mets in the BF group was higher than that in the non-BF group ( $42.69 \%$ vs. $34.76 \%, p<0.001$ ). BF was associated with increased risk of Mets (odds ratio [OR]: 1.4, 95\% confidence interval [Cl]: 1.18-1.65, $\mathrm{p}<0.001$ ). The BF group was at higher risks for diabetes (OR: 1.5, 95\%Cl: 1.14-1.98), hypertension (OR: $1.32,95 \% \mathrm{Cl}: 1.03-1.68)$, hypertriglyceridemia (OR: $1.42,95 \% \mathrm{Cl}: 1.02-1.99)$ and low high-density lipoprotein cholesterol (OR: 1.32, 95\%Cl: 1.06-1.65).
\end{abstract}

Conclusion: In this study, BF did not affect decreasing the prevalence of Mets and its components.

Keywords: Breastfeeding, Metabolic syndrome, Postmenopause, Parous women, Korea

\section{Background}

Metabolic syndrome (Mets) is a condition characterized by a cluster of cardiovascular risk factors, such as abdominal obesity, insulin resistance/glucose intolerance, dyslipidemia and hypertension, which increases the risk

\footnotetext{
* Correspondence: md3728@pednet.co.kr

2 Department of Pediatrics, Pusan National University Yangsan Hospital, 20, Geumo-ro, Mulgeum-eup, Yangsan-si, Gyeongsangnam-do 50612, Republic of Korea

Full list of author information is available at the end of the article
}

of developing cardiovascular disease and diabetes [1]. The prevalence of Mets is increasing worldwide in recent years $[2,3]$, and approximately $20-25 \%$ of adults have Mets in most countries [4]. The prevalence of Mets in the United States was $34.7 \%$ in $2011-2012$ (31.0\% in men and $36.6 \%$ in women) [5]. Li et al. [6] reported that the overall prevalence rate of Mets in China was $24.2 \%$ (24.6\% in men and $23.8 \%$ in women). Meanwhile, $23 \%$ of Japanese adults 30 years or older were diagnosed with Mets in 2011 [7]. In Korea, Mets was reported in 26.9\%

(c) The Author(s). 2021 Open Access This article is licensed under a Creative Commons Attribution 4.0 International License, which permits use, sharing, adaptation, distribution and reproduction in any medium or format, as long as you give appropriate credit to the original author(s) and the source, provide a link to the Creative Commons licence, and indicate if changes were made. The images or other third party material in this article are included in the article's Creative Commons licence, unless indicated otherwise in a credit line to the material. If material is not included in the article's Creative Commons licence and your intended use is not permitted by statutory regulation or exceeds the permitted use, you will need to obtain permission directly from the copyright holder. To view a copy of this licence, visit http://creativecommons.org/licenses/by/4.0/. The Creative Commons Public Domain Dedication waiver (http://creativecommons.org/publicdomain/zero/1.0/) applies to the data made available in this article, unless otherwise stated in a credit line to the data. 
of the entire population $(30 \%$ in men and $24.6 \%$ in women) [8]. Furthermore, women older than 60 years have a six times higher chance of Mets than those 20 to 39 years of age [9].

The benefits of breastfeeding (BF) on infants are well known such as reduced respiratory infections, gastrointestinal tract infections, necrotizing enterocolitis, sudden infant death syndrome, otitis media in children younger than 2 years, allergic disorders (asthma, atopic dermatitis), diabetes, obesity, acute leukemia, hypertension, and neurodevelopmental disorder $[10,11]$. BF also has benefits on maternal health such as reduced risk of breast cancer, ovarian cancer, type 2 diabetes [11-13].

However, the effects of BF on Mets are not clearly known. Understanding the relationship between BF and Mets is important for maternal long-term health benefits and disease prevention. In this study, we examined the association between BF and Mets and its components in postmenopausal parous women by analyzing populationbased data from the Korea National Health and Nutrition Examination Survey (KNHANES).

\section{Methods}

\section{Study population}

This study was conducted using the raw data of the KNHANES of from 2010 to 2016. The KNHANES is a statutory survey on people's health behavior, prevalence of chronic diseases, and food and nutrition practices consisting of a cross-sectional survey of a health interview survey, a health examination survey, and a nutrition survey. All survey protocols were approved by the Korea Centers for Disease Control \& Prevention. Written informed consent was obtained from all participants before the survey began.

Among the 56,632 participants, 11,396 were postmenopausal parous women. Of these, 1040 subjects were excluded, because 1022 had no information about Mets and 25 subjects did not provide BF data. Finally, 10,356 subjects with complete health interview survey and health examination survey in the final analysis were included.

\section{Study design}

This study employed a cross-sectional design. All data are available from the KNHANES database (http:// knhanes.cdc.go.kr/knhanes). Data were categorized into two groups according to breastfeeding status, the BF and non-BF groups. The BF group was determined from the following questionnaires: "Have you been breastfeeding for at least a month?" Medical history and lifestyle data, which included demographic (age, residence), socioeconomic (income level, education level), and lifestyle (use of contraceptives, exercise, smoking, drinking) information were collected using self-reported questionnaires.
Education level was divided into three categories: $\leq 9$ years (middle school or less), $10 \sim 12$ years (high school) and $\geq 13$ years (college or more). Income was classified into monthly household income quartiles to determine income level: 1: low, 2: middle low, 3: middle high, 4: high. Regular exercise was indicated as "yes" if the participants performed physical exercise for $\geq 30 \mathrm{~min}$ for at least 3 days per week. Smoking history was divided into three categories based on raw data: current, past, and never a smoker. Alcohol intake was divided into current, past and non-drinking based on monthly drinking rate (when drinking more than once a month for the last 1 year).

\section{Measurements}

All anthropometric measurements were taken by a team of experts by using a consistent, standardized methodology. Height was measured to the nearest $1 \mathrm{~mm}$ with a portable extensimeter (SECA225, SECA, Germany). Weight was measured to the nearest $0.1 \mathrm{~kg}$ with a calibrated balance scale (GL-6000-20, G-tech, Korea). Body mass index (BMI) was calculated as the ratio of weight to height ${ }^{2}\left(\mathrm{~kg} / \mathrm{m}^{2}\right)$. Waist circumference (WC) was measured to the nearest $0.1 \mathrm{~cm}$ at the narrowest circumference between the lower border of the rib cage and the uppermost borders of the iliac crest, at the end of expiration. Blood pressure (BP) was manually measured three times by well-trained nurses with a mercury sphygmomanometer (Baumanometer Wall Unit 33(0850), Baum, USA) after the participants relaxed for $5 \mathrm{~min}$ in a sitting position. Discarded the first measurement and the averages of the second and third measurements as used for analysis.

Blood samples were collected after at least of $8 \mathrm{~h}(12 \mathrm{~h}$ recommended) of fasting, immediately refrigerated after centrifugation, transferred to the Central Testing Institute in Seoul, Korea, and then assayed within $24 \mathrm{~h}$ after sampling. Fasting blood glucose, triglycerides, total cholesterol, low-density lipoprotein cholesterol (LDL-C) and high-density lipoprotein cholesterol (HDL-C) level were measured using a Hitachi Automatic Analyzer 7600210(Hitachi, Japan).

\section{Definition of metabolic syndrome}

The presence of Mets was defined according to the 2009 guideline of the International Diabetes Federation and the American Heart Association / National Heart, Lung, and Blood institute [14]. The criteria for abdominal obesity was defined by the Korean Society for the Study of Obesity [15]. Participants with three or more of the following five components were classified as having Mets: WC $\geq 85 \mathrm{~cm}$ for women, triglycerides $\geq 150 \mathrm{mg} / \mathrm{dL}$ or drug treatment for elevated triglycerides, HDL-C $<50$ $\mathrm{mg} / \mathrm{dL}$ for women or drug treatment for reduced HDL 
cholesterol, BP (systolic/diastolic BP $\geq 130 / 85 \mathrm{mmHg}$ or use of medication for hypertension, and fasting glucose $\geq 100 \mathrm{mg} / \mathrm{dL}$ or under treatment for diabetes.

\section{Statistical analysis}

All statistical analyses were conducted using Statistical Package for the Social Sciences (SPSS) complex sample procedures since KNHANES data were collected through a representative, stratified, and clustered sampling method.

The characteristics of the subjects are presented as estimate and 95\% confidence interval (CI). Continuous variables are expressed as mean \pm standard error. Chisquare test and independent $\mathrm{t}$-test were applied wherever appropriate. For the assessment of the odds ratios (ORs) of Mets and component of Mets according to BF, multivariate analysis was performed. For the regression analysis, several models were presented, controlling for potentially confounding variables. We first adjusted for age and height (model I), then for the variables in model I plus income, education and residence (model II), and lastly, for variables in model II plus oral contraceptives use, exercise, drinking and smoking (model III). Statistical analysis was conducted using SPSS version 21.0 (IBM Corp., Armonk, NY, US). For all analyses, $p$-values were two-tailed, and $p<0.05$ was considered statistically significant.

\section{Results}

Table 1 presents the general characteristics of the study participants according to BF. Socioeconomic information (house income, educational level and residence), life style information (oral contraceptives use, regular exercise, drinking and smoking), height, marital status, number of children, age at menarche and age at menopause were statistically significant.

Mets was present in $42 \%$ of the study participants. The prevalence of Mets in the BF group was higher than that in the non-BF group. Regarding the components of Mets, the BF group had significantly higher prevalence of abdominal obesity, hypertension, hypo-HDLcholesterolemia and higher BMI (Table 2).

The mean values for the Mets components according to $\mathrm{BF}$ are shown in Table 3. The average number of the five Mets components was higher in the BF group than that in the non-BF group. For each of the Mets components, the BF group had significantly higher $\mathrm{WC}$, and systolic and diastolic BP and lower total cholesterol and HDL-C level.

To determine the association between BF and Mets in all subjects, logistic regression analysis was performed (Table 4). BF was associated with increased risk of Mets in the crude model. The risk of Mets was not statistically significant in model I (after adjustment for age and height), model II (adjusted for age, height, income, education and residence), or model III (adjusted for model II plus oral contraceptive use, exercise, drinking and smoking).

Table 5 shows the ORs for the association of BF and Mets components. Compared with the non-BF group, the $\mathrm{BF}$ group was at higher risks for diabetes, hypertension, hypertriglyceridemia, and low HDL-C. After controlling for confounding factors, there was not statistically significant risk.

\section{Discussion}

In this population-based cross-sectional study, we investigated the association between BF and Mets and its components among Korean postmenopausal parous women using data from the KNHANES. There are some key findings in this study. First, the BF group had significantly higher prevalence of Mets. Second, the BF group had higher WC and BP and lower total cholesterol and HDL-C levels. Third, the risk of Mets was higher in the BF groups. Among the Mets components, the risk was higher for diabetes, hypertension and dyslipidemia. The results showed that BF does not affect reducing the risks of Mets and its components.

Multiple studies have examined the association between BF and the risk of Mets in postmenopausal women. Several studies found that BF appears to have a protective effect against the development of hypertension [16-19]. Zhang et al. [17] reported that both BF history and duration were associated with reduced risk of hypertension in middle-aged and older mothers. Furthermore, Schwarz et al. [19] reported that the beneficial effect of BF on hypertension seems to persists after menopause, as American women $\geq 50$ years who reported a BF history of more than 12 months had reduced risk of hypertension. Unexpectedly, we found that BF was not associated with a reduced risk of developing hypertension. Similarly, Natland et al. [16] found that mothers aged $<50$ years who had never breastfed had higher odds of hypertension than those who had breastfed $\geq 24$ months, but there were no clear associations in mothers $\geq 50$ years. Several studies have shown that the effect reducing the risk of hypertension does not appear to persist into older age $[18,20]$. Further studies are needed to better clarify the association between BF and hypertension.

In our study, BF group had lower total cholesterol and HDL-C level. Compared with the non-BF group, the BF group was at higher risk for hypertriglyceridemia and low HDL-C. However, the evidence of the long-term effect of $\mathrm{BF}$ on the lipid profile remains inconsistent. Schwarz et al. [19] reported that a long duration of BF resulted in reduced prevalence of hyperlipidemia. Similarly, a study reported a significant inverse association 
Table 1 Characteristics of participants

\begin{tabular}{|c|c|c|c|}
\hline Variables & Non-breastfeeding $(n=905)$ & Breastfeeding $(n=9451)$ & $P$ - value \\
\hline Age (year) $(n=10,356)$ & & & $<0.001$ \\
\hline$<50$ s & $18.61(15.36-22.36)$ & $8.17(7.36-9.05)$ & \\
\hline $50-59$ & $54.12(50.31-57.88)$ & $36.69(35.48-37.91)$ & \\
\hline $60-69$ & $19.61(16.93-22.60)$ & $29.12(28.07-30.20)$ & \\
\hline$\geq 70$ & $7.66(6.03-9.69)$ & $26.02(24.94-27.14)$ & \\
\hline Height $(\mathrm{cm})(n=10,350)$ & $156.04 \pm 0.23$ & $154.19 \pm 0.08$ & $<0.001$ \\
\hline Weight $(\mathrm{kg})(n=10,349)$ & $57.67 \pm 0.39$ & $57.79 \pm 0.12$ & 0.761 \\
\hline Marital state $(n=10,352)$ & & & $<0.001$ \\
\hline Single & $0.00(0.00-0.00)$ & $0.00(0.00-0.12)$ & \\
\hline Married & $79.74(76.54-82.60)$ & $70.97(69.78-72.13)$ & \\
\hline Divorced or separated & $20.26(17.40-23.46)$ & $28.99(27.83-30.18)$ & \\
\hline Age at menopause (year) $(n=9999)$ & $47.93 \pm 0.23$ & $48.96 \pm 0.07$ & $<0.001$ \\
\hline Age at menarche (year) $(n=10,273)$ & $14.76 \pm 0.09$ & $15.53 \pm 0.03$ & $<0.001$ \\
\hline Number of children $(n=10,356)$ & $3.54 \pm 0.07$ & $4.66 \pm 0.03$ & $<0.001$ \\
\hline No. breastfed children $(n=9451)$ & & $2.85 \pm 0.02$ & \\
\hline Breastfeeding duration (months) ( $n=9352$ ) & & $45.57 \pm 0.60$ & \\
\hline House Income $(n=10,280)$ & & & $<0.001$ \\
\hline 1 (low) & $14.01(11.49-16.98)$ & $30.20(28.92-31.50)$ & \\
\hline 2 (middle low) & $27.75(24.40-31.36)$ & $26.48(25.36-27.64)$ & \\
\hline 3 (middle high) & $25.71(22.40-29.32)$ & $22.64(21.57-23.75)$ & \\
\hline 4 (high) & $32.53(28.84-36.44)$ & $20.68(19.52-21.88)$ & \\
\hline Education level $(n=10,339)$ & & & $<0.001$ \\
\hline$\leq 9$ years & $36.43(32.74-40.28)$ & $69.56(68.10-70.98)$ & \\
\hline $10 \sim 12$ years & $39.99(36.23-43.87)$ & $21.27(20.16-22.42)$ & \\
\hline$\geq 13$ years & $23.58(20.15-27.40)$ & $9.17(8.33-10.07)$ & \\
\hline Occupation $(n=10,347)$ & & & 0.246 \\
\hline No & $53.80(49.72-57.83)$ & $56.31(54.90-57.70)$ & \\
\hline Yes & $46.20(42.17-50.28)$ & $43.69(42.30-45.10)$ & \\
\hline Residence $(n=10,356)$ & & & $<0.001$ \\
\hline Urban & $85.52(82.06-88.42)$ & $75.83(73.11-78.36)$ & \\
\hline Rural & $14.48(11.58-17.94)$ & $24.17(21.64-26.89)$ & \\
\hline Oral Contraceptives use $(n=10,346)$ & & & $<0.001$ \\
\hline No & $86.76(83.90-89.18)$ & $77.74(76.73-78.71)$ & \\
\hline Yes & $13.24(10.82-16.10)$ & $22.26(21.29-23.27)$ & \\
\hline Regular exercise $(n=10,345)$ & & & 0.014 \\
\hline No & $79.15(75.69-82.23)$ & $83.10(82.01-84.14)$ & \\
\hline Yes & $20.85(17.77-24.31)$ & $16.90(15.86-17.99)$ & \\
\hline Drinking status $(n=10,289)$ & & & $<0.001$ \\
\hline No & $40.38(36.76-44.11)$ & $48.88(47.54-50.23)$ & \\
\hline Past & $25.76(22.39-29.44)$ & $23.17(22.10-24.28)$ & \\
\hline Yes & $33.86(30.08-37.85)$ & $27.94(26.78-29.13)$ & \\
\hline Smoking status $(n=10,297)$ & & & $<0.001$ \\
\hline No & $87.65(84.65-90.13)$ & 92.33 (91.58-93.03) & \\
\hline Past & $4.35(3.03-6.21)$ & $3.50(3.05-4.02)$ & \\
\hline Yes & $8.00(5.90-10.77)$ & $4.17(3.66-4.74)$ & \\
\hline
\end{tabular}

Estimate (95\% confidence interval) for categorical variables and mean with standard error for continuous variables 
Table 2 Metabolic syndrome of participants

\begin{tabular}{|c|c|c|c|}
\hline Variable & Non-breastfeeding $(n=905)$ & Breastfeeding $(n=9451)$ & $P$-value \\
\hline Mets $(n=10,356)$ & & & $<0.001$ \\
\hline No & $65.24(61.55-68.75)$ & $57.31(56.05-58.56)$ & \\
\hline Yes & $34.76(31.25-38.45)$ & $42.69(41.44-43.95)$ & \\
\hline WC $(\geq 85 \mathrm{~cm})(n=10,356)$ & & & $<0.001$ \\
\hline No & $74.48(70.81-77.84)$ & $63.53(62.22-64.82)$ & \\
\hline Yes & $25.52(22.16-29.19)$ & $36.47(35.18-37.78)$ & \\
\hline FBS $(\geq 100 \mathrm{mg} / \mathrm{dl})$ or diabetes medication $(n=10,356)$ & & & 0.494 \\
\hline No & $62.25(58.48-65.88)$ & $60.92(59.70-62.13)$ & \\
\hline Yes & $37.75(34.12-41.52)$ & $39.08(37.87-40.30)$ & \\
\hline $\mathrm{HBP}(\geq 130 / 85 \mathrm{mmHg})$ or antihypertensive medication $(n=10,356)$ & & & $<0.001$ \\
\hline No & $55.88(52.04-59.66)$ & $41.66(40.35-42.98)$ & \\
\hline Yes & $44.12(40.34-47.96)$ & $58.34(57.02-59.65)$ & \\
\hline $\mathrm{TG}(\geq 150 \mathrm{mg} / \mathrm{dl})$ or drug treatment for elevated TG $(n=10,356)$ & & & 0.715 \\
\hline No & $67.98(64.23-71.52)$ & $68.70(67.53-69.84)$ & \\
\hline Yes & $32.02(28.48-35.77)$ & $31.30(30.16-32.47)$ & \\
\hline $\mathrm{HDL}(\leq 50 \mathrm{mg} / \mathrm{dl})$ or drug treatment for reduced $\mathrm{HDL}(n=10,356)$ & & & 0.018 \\
\hline No & $46.24(42.64-49.88)$ & $41.62(40.42-42.83)$ & \\
\hline Yes & $53.76(50.12-57.36)$ & $58.38(57.17-59.58)$ & \\
\hline $\operatorname{BMI}\left(\geq 25 \mathrm{~kg} / \mathrm{m}^{2}\right)(n=10,356)$ & & & $<0.001$ \\
\hline No & $71.26(67.56-74.69)$ & $62.36(61.17-63.54)$ & \\
\hline Yes & 28.74 (25.31-32.44) & 37.64 (36.46-38.83) & \\
\hline
\end{tabular}

Values are presented as estimate (95\% confidence interval)

Abbreviations: Mets Metabolic syndrome, WC Waist circumference, FBS Fasting blood sugar, HBP High blood pressure, TG Triglyceride, HDL High-density lipoprotein, $B M I$ Body mass index

between duration of $\mathrm{BF}$ and triglyceride, total cholesterol and LDL-C level [16]. However, the Coronary Artery Risk Development in Young Adults study [21] did not find a significant association of BF with total cholesterol, LDL-C or triglyceride concentration, but it showed a difference in HDL-C between women who breastfed for 3 months or more and women who breastfed for less than 3 months. Other studies reported that BF lowers total cholesterol and triglyceride, but HDL-C level was not related $[22,23]$.

The incidence of Mets is known to be influenced by various socio-economic factors such as education level, income level, wealth and type of job. Several studies that analyzed the association of education, income level and the prevalence of Mets, showed that the lower the socioeconomic level of women, the higher the prevalence of

Table 3 Mean and standard error value of components of metabolic syndrome

\begin{tabular}{|c|c|c|c|}
\hline Variable & Non-breastfeeding $(n=905)$ & Breastfeeding $(n=9451)$ & $P$-value \\
\hline No. of Mets components & $1.93 \pm 0.05$ & $2.24 \pm 0.02$ & $<0.001$ \\
\hline$W C(\mathrm{~cm})$ & $79.69 \pm 0.38$ & $82.21 \pm 0.14$ & $<0.001$ \\
\hline FBS (mg/dl) & $100.60 \pm 0.81$ & $101.83 \pm 0.31$ & 0.139 \\
\hline Total cholesterol (mg/dl) & $203.35 \pm 1.54$ & $199.55 \pm 0.45$ & 0.017 \\
\hline TG (mg/dl) & $137.87 \pm 4.52$ & $134.00 \pm 1.02$ & 0.405 \\
\hline $\mathrm{HDL}(\mathrm{mg} / \mathrm{dl})$ & $52.79 \pm 0.46$ & $51.08 \pm 0.16$ & $<0.001$ \\
\hline LDL (mg/dl) & $122.96 \pm 2.61$ & $121.11 \pm 0.76$ & 0.495 \\
\hline Systolic BP (mmHg) & $122.17 \pm 0.75$ & $126.33 \pm 0.27$ & $<0.001$ \\
\hline Diastolic BP (mmHg) & $76.91 \pm 0.44$ & $75.79 \pm 0.14$ & 0.014 \\
\hline
\end{tabular}

Values are presented as Mean \pm standard error

Abbreviations: Mets Metabolic syndrome, WC Waist circumference, FBS Fasting blood sugar, TG Triglyceride, HDL High-density lipoprotein, LDL Low-density lipoprotein, BP Blood pressure 
Table 4 Logistic regression model of breastfeeding for metabolic syndrome

\begin{tabular}{llll}
\hline & Non-breastfeeding & Breastfeeding (Odds ratio(95\%CI)) & $P$-value \\
\hline Crude & Reference & $1.40(1.18-1.65)$ & $<0.001$ \\
Model I & Reference & $0.97(0.81-1.16)$ & 0.737 \\
Model II & Reference & $0.84(0.70-1.01)$ & 0.064 \\
Model III & Reference & $0.84(0.72-1.01)$ & 0.063 \\
\hline
\end{tabular}

Model I; adjusted for age, height

Model II: adjusted for age, height, income, education, residence

Model III: adjusted for age, height, income, education, residence and use of oral contraceptives, exercise, drinking, smoking

Mets [24-26]. In addition, the lower socio-economic levels lead to increased insulin resistance and abdominal obesity due to poor lifestyle, nutritional imbalance, stress, etc., resulting in health problems such as Mets and cardiovascular disease [27]. The lower the income levels tend to consume low-cost, high-calorie foods that contain more such things as fat, added sugar, and refined grains [28]. Women with lower education tend to give birth to more children, and these pregnancies and childbirth had been reported to cause metabolic disorders accompanied by increased abdominal obesity, decreased HDL-C, and psychological depression during postpartum and child rearing [29]. In the BF group, many of the subjects had lower household income and education level than non-BF group. Thus, the BF group had higher prevalence of central obesity, hypertension and dyslipidemia and higher risks of diabetes, hypertension and dyslipidemia than the non-BF group. Our results showed that social and environmental factors are more important than BF in the prevalence of Mets.

Table $\mathbf{5}$ Logistic regression model of each component of metabolic syndrome according to breastfeeding

\begin{tabular}{|c|c|c|c|}
\hline & Non-Breastfeeding & Breastfeeding (OR(95\%Cl)) & $P$-value \\
\hline \multicolumn{4}{|l|}{ Crude } \\
\hline$W C(\geq 85 \mathrm{~cm})$ & 1 & $1.14(0.78-1.67)$ & 0.506 \\
\hline High FBS ( $\geq 100 \mathrm{mg} / \mathrm{dl}$ ) & 1 & $1.50(1.14-1.98)$ & 0.004 \\
\hline High $B P(\geq 130 / 85$ mmHg $)$ & 1 & $1.32(1.03-1.68)$ & 0.029 \\
\hline Low HDL ( $\leq 50 \mathrm{mg} / \mathrm{dl})$ & 1 & $1.32(1.06-1.65)$ & 0.013 \\
\hline High TG ( $\geq 150$ mg/dl) & 1 & $1.42(1.02-1.99)$ & 0.039 \\
\hline \multicolumn{4}{|l|}{ Model I } \\
\hline$W C(\geq 85 \mathrm{~cm})$ & 1 & $0.79(0.52-1.20)$ & 0.271 \\
\hline High FBS ( $\geq 100 \mathrm{mg} / \mathrm{dl}$ ) & 1 & $1.11(0.83-1.50)$ & 0.469 \\
\hline High $B P(\geq 130 / 85$ mmHg) & 1 & $1.10(0.85-1.42)$ & 0.469 \\
\hline Low HDL ( $\leq 50$ mg/dl) & 1 & $0.91(0.72-1.16)$ & 0.451 \\
\hline High TG ( $\geq 150$ mg/dl) & 1 & $0.84(0.59-1.19)$ & 0.321 \\
\hline \multicolumn{4}{|l|}{ Model II } \\
\hline$W C(\geq 85 \mathrm{~cm})$ & 1 & $0.76(0.50-1.16)$ & 0.209 \\
\hline High FBS ( $\geq 100 \mathrm{mg} / \mathrm{dl}$ ) & 1 & $1.01(0.75-1.36)$ & 0.931 \\
\hline High $B P(\geq 130 / 85$ mmHg $)$ & 1 & $0.99(0.76-1.28)$ & 0.921 \\
\hline Low HDL ( $\leq 50$ mg/dl) & 1 & $0.81(0.64-1.03)$ & 0.079 \\
\hline High TG ( $\geq 150$ mg/dl) & 1 & $0.74(0.51-1.06)$ & 0.095 \\
\hline \multicolumn{4}{|l|}{ Model III } \\
\hline$W C(\geq 85 \mathrm{~cm})$ & 1 & $0.76(0.49-1.17)$ & 0.216 \\
\hline High FBS ( $\geq 100 \mathrm{mg} / \mathrm{dl})$ & 1 & $1.03(0.76-1.39)$ & 0.849 \\
\hline High $\mathrm{BP}(\geq 130 / 85 \mathrm{mmHg})$ & 1 & $1.03(0.79-1.34)$ & 0.837 \\
\hline Low HDL ( $\leq 50 \mathrm{mg} / \mathrm{dl})$ & 1 & $0.80(0.63-1.02)$ & 0.070 \\
\hline High TG ( $\geq 150$ mg/dl) & 1 & $0.72(0.50-1.04)$ & 0.081 \\
\hline
\end{tabular}

1. Model I: adjusted for age, height

2. Model II: adjusted for age, height, income, education, residence

3. Model III: adjusted for age, height, income, education, residence and oral contraceptives, exercise, drinking, smoking

Abbreviations: WC Waist circumference, FBS Fasting blood sugar, BP Blood pressure, HDL High-density lipoprotein, TG Triglyceride 
This study has some limitations. First, the crosssectional design of the KNHANES made it difficult to conclude a causal relationship between $\mathrm{BF}$ and the prevalence of Mets components. Second, self-reporting of BF duration, smoking, drinking and exercise pattern recall may lead to misclassification and measurement error. Furthermore, because it was a survey study, it was not possible to analyze the factors affecting Mets according to the duration of BF, lifestyle and dietary pattern. No information was available about the pregnancy state, such as gestational weight gain or postpartum weight retention, in the current study. Despite these limitations, our study has some strengths. First, we analyzed a nationally representative large sample from the KNHA NES. Second, this data were adjusted for confounding factors in our models. These results are especially helpful in establishing evidence-based health policies on women's health.

\section{Conclusion}

In this population-based study of postmenopausal parous Korean women, BF did not affect decreasing prevalence of Mets or its components. It also showed that social and environmental factors are more important than BF in the prevalence of Mets. Lifestyle changes, such as weight reduction, regular exercise and healthy dietary habits should be emphasized.

\section{Abbreviations}

Mets: Metabolic syndrome; BF: Breastfeeding; KNHANES: Korea National Health and Nutrition Examination Survey; WC: Waist circumference; BMI: Body mass index; BP: Blood pressure; HDL-C: High density lipoprotein cholesterol; LDL-C: Low density lipoprotein-cholesterol; Cl: Confidence interval; OR: Odds ratio

\section{Acknowledgments}

Not applicable.

\section{Authors' contributions}

Conceptualization: KTH. Data curation: KTH, LJS. Formal analysis: KTH, LJS. Investigation: KTH, LS. Methodology: KTH, LJS. Writing-original draft: KTH. Writing-review \& editing: KTH, L JS. The author(S) read and approved the final manuscript.

\section{Funding}

Not applicable.

\section{Availability of data and materials}

The datasets generated and /or analyzed during the current study are available from the Korea National Health and Nutrition Examination Survey (http://knhanes.cdc.go.kr/knhanes).

\section{Declarations}

\section{Ethics approval and consent to participate}

All of the participants in the KNHANES were informed that they had been randomly chosen to participate in the survey with the right to participate in the further analyses, and signed an informed consent form. As this was a cross-sectional study that used and analyzed only non-identifiable data from KNHANES (http://knhanes.cdc.go.kr/knhanes/), ethical approval was not required.
Consent for publication

Not applicable.

\section{Competing interests}

The authors have no potential conflict of interest to disclose.

\section{Author details}

${ }^{1}$ Department of Pediatrics, Samsung Changwon Hospital, Sungkyunkwan University School of Medicine, Changwon, Republic of Korea. ${ }^{2}$ Department of Pediatrics, Pusan National University Yangsan Hospital, 20, Geumo-ro, Mulgeum-eup, Yangsan-si, Gyeongsangnam-do 50612, Republic of Korea.

Received: 29 December 2020 Accepted: 9 May 2021

Published online: 19 May 2021

\section{References}

1. Isomaa B, Almgren P, Tuomi T, Forsen B, Lahti K, Nissen M, et al. Cardiovascular morbidity and mortality associated with the metabolic syndrome. Diabetes Care. 2001;24(4):683-9. https://doi.org/10.2337/diaca re.24.4.683.

2. Borch-Johnsen K. The metabolic syndrome in a global perspective. The public health impact-secondary publication. Dan Med Bull. 2007;54(2):157-9.

3. Grundy SM. Metabolic syndrome pandemic. Arterioscler Thromb Vasc Biol. 2008;28(4):629-36. https://doi.org/10.1161/ATVBAHA.107.151092.

4. International Diabetes Federation. The IDF consensus worldwide definition of the metabolic syndrome. 2006; Available from: http://www.idf.org/webda ta/docs/IDF_Meta_def_final.pdf. Accessed 20 May 2020.

5. Aguilar M, Bhuket T, Torres S, Liu B, Wong RJ. Prevalence of the metabolic syndrome in the United States, 2003-2012. JAMA. 2015;313(19):1973-4. https://doi.org/10.1001/jama.2015.4260.

6. Li Y, Zhao L, Yu D, Wang Z, Ding G. Metabolic syndrome prevalence and its risk factors among adults in China: a nationally representative crosssectional study. PLoS One. 2018;13(6):e0199293. https://doi.org/10.1371/ journal.pone.0199293.

7. Kim J, Tanabe K, Yokoyama N, Zempo H, Kuno S. Objectively measured light-intensity lifestyle activity and sedentary time are independently associated with metabolic syndrome: a cross-sectional study of Japanese adults. Int J Behav Nutr Phys Act. 2013;10:30

8. Kim HR, Han MA. Association between serum liver enzymes and metabolic syndrome in Korean adults. Int J Environ Res Public Health. 2018;15(8):1658. https://doi.org/10.3390/ijerph15081658.

9. Ervin RB. Prevalence of metabolic syndrome among adults 20 years of age and over, by sex, age, race and ethnicity, and body mass index: United States. Natl Health Stat Rep. 2009:13:1-7.

10. Kramer MS, Kakuma R. Optimal duration of exclusive breastfeeding. Cochrane Database Sys Rev. 2012;8:1-44.

11. Victoria CG, Bahl R, Barros AJ, Franca GV, Horton S, Kraevec J, et al. Breastfeeding in the 21st century: epidemiology, mechanisms, and lifelong effect. Lancet. 2016;387(10017):475-90. https://doi.org/10.1016/S0140-6736(1 5)01024-7.

12. Chowdhury R, Sinha B, Sankar MJ, Taneja S, Bhandari N, Rollins N, et al. Breastfeeding and maternal health outcomes: a systematic review and meta-analysis. Acta Paediatr. 2015;104(467):96-113. https://doi.org/10.1111/a pa.13102.

13. Section on Breastfeeding. Breastfeeding and the use of human milk Pediatrics. 2012;129(3):e827-41. https://doi.org/10.1542/peds.2011-3552.

14. Alberti KG, Eckel RH, Grundy SM, Zimmet PZ, Cleeman JI, Donato K, et al. Harmonizing the metabolic syndrome: a joint interim statement of the International Diabetes Federation Task Force on Epidemiology and Prevention; National Heart, Lung, and Blood Institute; American Heart Association; World Heart Federation; International Atherosclerosis Society; and International Association for the Study of Obesity. Circulation. 2009; 120(16):1640-5. https://doi.org/10.1161/CIRCULATIONAHA.109.192644.

15. Lee SY, Park HS, Kim DJ, Han JH, Kim SM, Cho GJ, et al. Appropriate waist circumference cutoff points for central obesity in Korean adults. Diabetes Res Clin Pract. 2007;75(1):72-80. https://doi.org/10.1016/j.diabres.2006.04.013.

16. Natland ST, Nilsen TI, Midthjell K, Andersen LF, Forsmo S. Lactation and cardiovascular risk factors in mothers in a population-based study. Int Breastfeed J. 2012;7(1):8. https://doi.org/10.1186/1746-4358-7-8. 
17. Zhang BZ, Zhang H, Liu HH, Li HJ, Wang S. Breastfeeding and maternal hypertension and diabetes: a population-based cross-sectional study. Breastfeed Med. 2015;10(3):163-7. https://doi.org/10.1089/bfm.2014.0116.

18. Lupton SJ, Chiu CL, Lujic S, Hennessy A, Lind JM. Association between parity and breastfeeding with maternal high blood pressure. Am J Obstet Gynecol. 2013;208(6):454.e1-7.

19. Schwarz EB, Ray RM, Stuebe AM, Allison MA, Ness RB, Freiberg MS, et al. Duration of lactation and risk factors for maternal cardiovascular disease. Obstet Gynecol. 2009;113(5):974-82. https://doi.org/10.1097/01.AOG.000034 6884.67796.ca.

20. Ram KT, Bobby P, Hailpern SM, Lo JC, Schocken M, et al. Duration of lactation is associated with lower prevalence of the metabolic syndrome in midlife - SWAN, the Study of Women's Health Across the Nation. Am J Obstet Gynecol. 2008;198(3):268.e1-6.

21. Gunderson EP, Lewis CE, Wei GS, Whitmer RA, Quesenberry CP, Sidney S Lactation and changes in maternal metabolic risk factors. Obstet Gynecol. 2007;109(3):729-38. https://doi.org/10.1097/01.AOG.0000252831.06695.03.

22. McClure CK, Catov JM, Ness RB, Schwarz EB. Lactation and maternal subclinical cardiovascular disease among premenopausal women. Am J Obstet Gynecol. 2012;207(1):46.e1-8.

23. Torris C, Thune I, Emaus A, Finstad SE, Bye A, Furberg AS, et al. Duration of lactation, maternall metabolic profile, and body composition in the Norwegian EBAl-study. Breastfeed Med. 2013;8(1):8-15. https://doi.org/10.1 089/bfm.2012.0048.

24. Santos AC, Ebrahim S, Barros H. Gender, socio-economic status and metabolic syndrome in middle-aged and old adults. BMC Public Health. 2008;8(1):62. https://doi.org/10.1186/1471-2458-8-62.

25. Marquezine GF, Oliveira CM, Pereira AC, Krieger JE, Mill JG. Metabolic syndrome determinants in an urban population from Brazil: social class and gender-specific interaction. Int J Cardiol. 2008;129(2):259-65. https://doi. org/10.1016/j.jijcard.2007.07.097.

26. Dallongeville J, Cottel D, Ferrieres J, Arveiler D, Bingham A, Ruidavets JB, et al. Household income is associated with the risk of metabolic syndrome in a sex-specific manner. Diabetes Care. 2005;28(2):409-15.

27. Kim DJ. The association of socioeconomic status with diabetes, and cardiovascular disease. Korean J Med. 2008;74(4):349-57.

28. Darmon N, Briend A, Drewnowski A. Energy-dense diets are associated with lower diet costs: a community study of French adults. Public Health Nutr. 2004;7(1):21-7. https://doi.org/10.1079/PHN2003512.

29. Loucks EB, Rehkopf DH, Thurston RC, Kawachi I. Socioeconomic disparities in metabolic syndrome differ by gender: evidence from NHANES III. Ann Epidemiol. 2007;17(1):19-26. https://doi.org/10.1016/j.annepidem.2006.07. 002

\section{Publisher's Note}

Springer Nature remains neutral with regard to jurisdictional claims in published maps and institutional affiliations.

Ready to submit your research? Choose BMC and benefit from:

- fast, convenient online submission

- thorough peer review by experienced researchers in your field

- rapid publication on acceptance

- support for research data, including large and complex data types

- gold Open Access which fosters wider collaboration and increased citations

- maximum visibility for your research: over $100 \mathrm{M}$ website views per year

At $\mathrm{BMC}$, research is always in progress.

Learn more biomedcentral.com/submissions 